\title{
Uma proposta de sequência didática para ensino de dilatometria com utilização de paródia
}

\author{
Railene Azevedo da Fonseca ${ }^{1}$, Francisco Eulálio A. Santos², Bianca Martins Santos ${ }^{3}$ e Lídia da Rocha Silva ${ }^{4}$ \\ 1, 2,3,4 Universidade Federal do Acre (UFAC) \\ Palavras Chave: Ensino e aprendizagem em Física; Paródias; Lúdico.
}

\section{Introdução}

O ensino de Física pode ser associado a atividades que levam à memorização de informações, fórmulas, estruturas e conhecimentos que limitam a aprendizagem, desmotivando o aluno quanto à Física. Os recursos didáticos são considerados elementos essenciais no trabalho dos conteúdos escolares com os alunos, pois permite o contato com diversas formas de aprendizagem, cuja aplicação permeia aspectos motivacionais, estimulantes, desafiadores e colaboradores. Nesse sentido, objetiva-se no trabalho relatar a utilização de paródias como estratégia de ensino e aprendizagem para abordagem de conteúdos de Física, dando enfoque ao uso da contextualização. "Para Ribas e Guimarães (2004, p. 2), quando o aluno sente prazer na atividade proposta pelo professor, a aprendizagem e o processo cognitivo de construção do conhecimento são estimulados". Segundo os autores, a construção de conhecimentos significativos está ligado a algo que chama atenção e que revela coisas com as quais o indivíduo identifica-se e que pode despertar sensações ou emoções. Para eles, a base de tal reflexão está associada ao estímulo da crítica e a vivência de cada um. Assim, “...o uso da música na forma de paródias tem a possibilidade de quebrar a rotina escolar baseada no modelo tradicional de ensino, possibilitando momentos de alegria e descontração durante a aula, estimulando a atenção e a responsabilidade necessárias à aprendizagem" (SILVEIRA; KIOURANIS, 2008, p. 29).

\section{Metodologia e Sequência Didática}

O objetivo dessa sequência é elaborar, implementar e avaliar uma sequência didática que busca propor um processo de ensino e aprendizagem dos conceitos que envolvem o tema de Dilatação Térmica, com apoio da Paródia elaborada a partir da música, Farra, Pinga e Foguete dos artistas Bruno e Barretto. A sequência está dividida em cinco momentos, descritos a seguir.

Primeiro Momento: Problematização com uma imagem da Figura 1. A imagem mostra um mecânico com bastante dificuldade em desatarraxar a porca, logo em seguida o outro mecânico resolveu solucionar o problema com fogo, explique porque esse procedimento foi válido? Qual é o fenômeno que explica o que é observado na imagem?

Figura 1: Dilatação Térmica

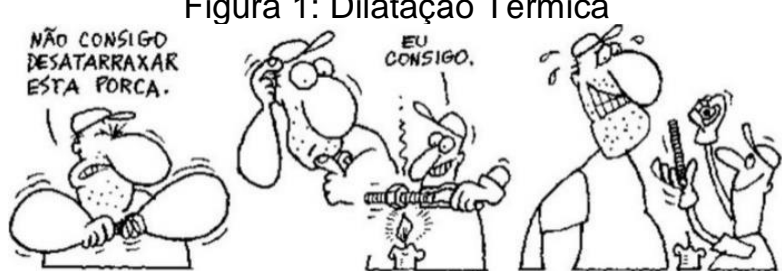

Fonte: http://3.bp.blogspot.com/-K0RUmD582VA/Te1PDWEsD7I/AAAAAAAAACk/nhLrce3QGvk/s1600/dilatacao_termica_solidos_liquidos.jpg

Segundo Momento: Será entregue a paródia impressa para cada aluno, com o tema Dilatação térmica, onde será solicitado a formação de grupos de no máximo 6 alunos, logo em seguida os estudantes deverão destacar as palavras chave da paródia e explicar, com base nos conhecimentos prévios, relacionando o que eles sabem sobre o conteúdo que os mesmos destacaram. Tal etapa tem a finalidade de verificar as concepções dos alunos acerca da temática e fazer com que os alunos percebam os conteúdos, a fim de que o aprendizado seja considerado significativo.

Terceiro Momento: Explicação da aula expositiva, mostrando os conceitos e equações que envolvam os conteúdos de Dilatação térmica, de forma a promover situações em que os discentes relacionem o conteúdo com a realidade que o cerca. 
Quarto Momento: Aplicação da Paródia, onde os estudantes deverão cantar. Nesse momento, a paródia fará mais sentido, pois o conteúdo será visto em três situações diferentes: na Figura 2, na letra da paródia, na abordagem teórica do conteúdo e finalizando com a paródia cantada.

Figura 2: Paródia sobre Dilatação Térmica.

Paródia dilatacão térmica: linear, superficial e volumétrica

Se as moléculas de uma substância se agitar

Pode ficar sabendo, seu tamanho vai aumentar

Se dilatar uma dimensão, será a linear

E dilatando as duas, será superficial

E dilatando as três, a volumétrica assume

Beta é duas vezes o alpha $(\beta=2 . \alpha)$ e Gamma é três $(\gamma=3 . \alpha)$

\section{Refrão}

Se a Temperatura variar e o tamanho aumentar Dilatação térmica, vou aplicar

Se for linear, use pra resolver $\Delta l=l_{o} . \alpha . \Delta t$

Temperatura mudando, e o tamanho aumentando

Dilatação térmica, estou demonstrando

Com duas dimensões, use pra resolver, $\Delta A=A_{o} . \beta . \Delta t$

Temperatura variando, e o tamanho aumentando

Dilatação térmica, estou estudando

Se for volumétrica, use pra resolver, $\Delta V=V_{0} \cdot \gamma \cdot \Delta t$

Fonte: Próprio autor.

Quinto Momento: Como forma de avaliar o uso da paródia, será utilizado um questionário para verificar se houve indícios de aprendizagem dos alunos contendo oito questões, seis de caráter dissertativo e duas objetivas como mostra na Figura 3.

Figura 3: Questionário

1. Em sua opinião, as paródias podem ser utilizadas para facilitar a aprendizagem dos conceitos e fórmulas de física? ( ) Sim ( ) Não ( ) Às vezes

2. O uso de paródias contribuiu para aprendizagem do conteúdo de Dilatação Térmica? Justifique:

3. O que você entende por dilatação térmica?

4.Qual é a diferença entre a dilatação linear, dilatação superficial e a dilatação volumétrica?

5. Você já viu que em calçadas ou pontes há trincas e tem sempre uma pequena abertura ou separação? Você sabe por quê?

6. Explique o porquê entre as partes dos trilhos de uma ferrovia existe um intervalo (espaço) entre eles?

7.Quando há um excesso de corrente elétrica, o disjuntor de um sistema elétrico desarma. Você sabe porquê?

8.Uma barra de 10 metros de alumínio a uma temperatura inicial de $20^{\circ} \mathrm{C}$ fica exposta ao sol, sendo sua temperatura elevada para $40^{\circ} \mathrm{C}$. Sabendo que o coeficiente de dilatação do alumínio é $\alpha=$ $22 \times 10^{-6}{ }^{\circ} \mathrm{C}^{-1}$, calcule a dilatação sofrida pela barra.
a) $4,4 \times 10^{-3} \mathrm{~m}$
b) $3,2 \times 10^{-5} \mathrm{~m}$
c) $1,2 \times 10^{-4} \mathrm{~m}$
d) $2,4 \times 10^{-3} \mathrm{~m}$

\section{Resultados esperados}

A sequência será aplicada em duas turmas de segundo ano do Ensino Médio em uma escola da rede privada de Rio Branco, Acre, dentro do projeto temático sobre: Uma proposta de sequência didática para o ensino de Dilatometria. Acredita-se que a atividade tenha uma função de dinamizar as aulas, que pode proporcionar aos alunos uma maior interação e aprendizagem.

\section{Referências}

SILVEIRA, M. P.; KIOURANIS, N. M. M. A música e o ensino de química. Química nova na escola, n. 28, p. 28-31, 2008.

RIBAS, L.C.C.; GUIMARÃES, L.B. Cantando o mundo vivo: aprendendo biologia no pop-rock brasileiro. Ciência e Ensino, Campinas, n. 12, 2004. 